\title{
Qualidade da água de córregos sob influência da ocupação antrópica: o caso das águas urbanas e periurbanas de Santarém-PA
}

Os recursos hídricos próximos à área urbana de Santarém/PA vêm sofrendo grandes impactos, podendo ser alterados por diversos fatores, seja por elementos naturais (geologia, vegetação, solos e clima) e principalmente pelo conjunto de atividades antrópicas, alterando sensivelmente os processos biológicos, físicos e químicos dos recursos hídricos. Devido à perda de quantidade e qualidade das águas com ocupação solo, disposição inadequada de resíduos e a destruição de sua vegetação ripária. Alguns estudos sobre a água feita em áreas urbanas mostram interferência antrópica de forma qualitativa e quantitativa nas suas características químicas, físicas e biológicas dos sistemas hídricos. Um dos principais tipos de poluição aquática é a que se caracteriza pela presença de matéria orgânica na água, com isso, quanto maior a quantidade de material orgânico disponível, maior será a população de organismos que a decompõe, portanto, maior será a quantidade de oxigênio consumido. $O$ estudo tem como objetivo determinar os parâmetros-físico químico e bacteriológicos indicadores de qualidade da água do canal principal de onze microbacias hidrográficas da área urbana e periurbana do Município de Santarém.

Palavras-chave: Matéria orgânica; Parâmetros físico-químicos; Poluição aquática; Qualidade da água.

\section{Stream water quality under the influence of anthropic occupation: the case of urban and periurban waters in Santarém-PA}

\begin{abstract}
The water resources close to the urban area of Santarém/PA have been suffering great impacts, being able to be altered by several factors, either by natural elements (geology, vegetation, soils and climate) and mainly by the set of human activities, significantly altering the processes biological, physical and chemical aspects of water resources. Due to the loss of quantity and quality of water with soil occupation, inadequate waste disposal and the destruction of its riparian vegetation. Some studies on water made in urban areas show anthropic interfer-ence in a qualitative and quantitative way in their chemical, physical and biological characteristics of water sys-tems. One of the main types of aquatic pollution is that which is characterized by the presence of organic mat-ter in the water, therefore, the greater the amount of organic material available, the greater the population of organisms that decomposes it, therefore, the greater the amount of oxygen consumed. The study aims to de-termine the physical-chemical and bacteriological parameters of water quality in the main channel of eleven hydrographic microbasins in the urban and peri-urban areas of the Municipality of Santarém.
\end{abstract}

Keywords: Organic matter; Physical-chemical parameters; Water pollution; Water quality.

Topic: Desenvolvimento, Sustentabilidade e Meio Ambiente

Reviewed anonymously in the process of blind peer.
Received: 04/12/2020

Approved: 21/12/2020
Sérgio Gouvêa de Melo (iD

Universidade Federal do Oeste do Pará, Brasil

http://lattes.cnpq.br/0148689717369496

http://orcid.org/0000-0002-6946-6672

sergiomeloccm@hotmail.com

Lucinewton Silva Moura (iD)

Universidade Federal do Oeste do Pará, Brasil

http://lattes.cnpq.br/2577499231565227

http://orcid.org/0000-0002-9266-946X

lucinewton.moura@yahoo.com.br

\section{Ruy Bessa Lopes (ib}

Universidade Federal do Oeste do Pará, Brasil

http://lattes.cnpq.br/4195469692527946

http://orcid.org/0000-0002-4806-8835

ruybessa@yahoo.com.br

\author{
Zaqueu dos Santos (iD) \\ Universidade Federal do Oeste do Pará, Brasil \\ http://lattes.cnpq.br/7837791702360862 \\ http://orcid.org/0000-0003-4877-6177 \\ zaquei_sant@hotmail.com \\ Rodolfo Maduro Almeida (iD \\ Universidade Federal do Oeste do Pará, Brasil \\ http://lattes.cnpq.br/1527651015984510 \\ http://orcid.org/0000-0003-4564-825X \\ rodolfomaduroalmeida@gmail.com \\ Júlio Tota da Silva (iD \\ Universidade Federal do Oeste do Pará, Brasil \\ http://lattes.cnpq.br/3850475880747662 \\ http://orcid.org/0000-0003-4093-6586 \\ totaju@gmail.com
}

Referencing this:

MELO, S. G.; MOURA, L. S.; LOPES, R. B.; SANTOS, Z.; ALMEIDA, R. M.; SILVA, J. T.. Qualidade da água de córregos sob influência da ocupação antrópica: o caso das águas urbanas e periurbanas de Santarém-PA. Revista Ibero Americana de Ciências Ambientais, v.11, n.7, p.569576, 2020. DOI: http://doi.org/10.6008/CBPC2179$\underline{6858.2020 .007 .0044}$ 


\section{INTRODUÇÃO}

A Região Amazônica sofreu e vem sofrendo vertiginosamente com o crescimento urbano muitas vezes desordenado. Às vezes incentivadas por políticas públicas que estimularam a migração populacional a partir de várias partes do país para a região, com divulgações sobre a amazônica, que seria um manancial inesgotável de matérias-primas, espaço aberto à ocupação e à transformação, um manancial que poderia alimentar a crescente população mundial e propiciar enormes riquezas a um país que aspirava grandeza e progresso (SOUZA, 2020). O que levou a um acelerado crescimento populacional desordenado, e um aumento na utilização dos recursos naturais, acarretando maior poluição, degradação dos recursos hídricos, degradação do solo e gerando problemas socioambientais.

Em um estudo realizado pelo Instituto Trata Brasil (2020) foi verificado que a falta de saneamento tem implicações imediatas sobre a saúde e a qualidade de vida da população que mora em áreas degradadas do ponto de vista ambiental.

O uso da água pela sociedade humana visa a atender suas necessidades pessoais, atividades econômicas (agrícolas e industriais) e sociais. No entanto, os recursos hídricos degradam-se com atividades antropogênicas decorrentes do tipo de ocupação do solo, como a presença de residências ou construção de obra pública em suas margens, lançamento in natura de efluentes domésticos, disposição inadequada de resíduos sólidos, supressão da mata ciliar oferecem grandes impactos (PINTO et al., 2009).

Os córregos e os rios são malhas complexas de um sistema que forma as bacias hídricas, caracterizados como escoadouros naturais das áreas de drenagens que formam um sistema fundamental para as bacias. Sua complexibilidade deve-se ao uso da terra, geologia, tamanho e formas das bacias de drenagem, além das condições climáticas locais (TOLEDO et al., 2002).

Os recursos hídricos podem ser alterados por diversos fatores, envolvendo a sua qualidade e quantidade de água das nascentes, seja por elementos naturais (geologia, vegetação, solos e clima) e, sobretudo, pelo conjunto de atividades antrópicas, de forma a alterar sensivelmente os processos biológicos, físicos e químicos dos recursos hídricos (OLIVEIRA et al., 2020). Pinto et al. (2009) sugere que a ação antrópica interfere qualitativa e quantitativamente à medida que afeta as características químicas, físicas e biológicas dos sistemas hídricos.

Em alguns estudos feitos nos córregos na área urbana da cidade de Santarém, Santos et al. (2020) constata a contaminação de origem antrópica, com aumento crescente no déficit de oxigênio, valores mínimos de fotossíntese e contribuição da nitrificação para o consumo de oxigênio dissolvido, podendo indicar lançamentos de esgoto doméstico devido à presença de residências próximas ao curso d'água é até mesmo outras fontes de carbono que possam ser drenadas para o córrego através da poluição difusa.

O ciclo hidrológico da água possui algumas fases básicas, sendo estas: a precipitação, a interceptação, a evaporação, a evapotranspiração, a infiltração, o escoamento superficial e o escoamento subterrâneo (JUSTINO et al., 2011). Com o aumento do despejo de resíduos aquosos e sólidos lançados nos pequenos cursos d'água e rios que alimentam a drenagem e a destruição das suas matas ciliares, se observa 
secundariamente a perda da quantidade e qualidade das águas urbanas.

Em águas naturais, a demanda bioquímica de oxigênio representa a demanda potencial de oxigênio dissolvido que poderá ocorrer devido à estabilização dos compostos orgânicos biodegradáveis (MANOEL et al., 2019). A poluição orgânica é caracterizada pela presença de grande carga de matéria orgânica na água levando a um crescimento na população de organismos decompositores de matéria, alterando o consumo de oxigênio, afetando a vida aquática (SPERLING, 1996). Dentre diversas ferramentas, destaca-se o Índice de Qualidade da Água (IQA), que é uma importante metodologia para mensurar o padrão das águas nacionais (ANA, 2011).

A poluição hídrica citada no estudo por meio das atividades antropogênicas ocasiona alterações físico-químicas e biológicas nas águas das águas urbanas. Passivos e agravos (doenças de via hídrica) são emergentes nas populações domiciliadas nas proximidades dos cursos d'água que culturalmente utilizam este espaço para diversos fins, tais como: abastecimento doméstico, assepsia pessoal, lavagens de roupas e veículos, funções de lazer a irrigações de suas plantações. Considerando o cenário exposto, este trabalho teve como objetivo determinar os parâmetros-físico químico e bacteriológicos indicadores de qualidade da água de onze microbacias hidrográficas por meio do canal principal na área urbana e periurbana de Santarém, a fim de auxiliar o poder público nas suas políticas voltadas a segurança hídrica dos mananciais.

\section{METODOLOGIA}

\section{Amostragem e Coleta}

Para a avaliação da qualidade das águas superficiais foram coletadas amostras de água em onze diferentes pontos, da região urbana do município de Santarém e entorno. Os respectivos pontos estão assinalados conforme mostra a Figura 1. Dos onze pontos escolhidos, dois estão no interior do perímetro urbano, estando os demais pontos situados na área periurbana.

As coletas das amostras das águas superficiais foram realizadas conforme o indicado pela Associação Brasileira de Normas Técnicas, NBR 9898, de junho 1987, a qual estabelece condições para a coleta e a preservação de amostras de água, de corpos receptores interiores superficiais.

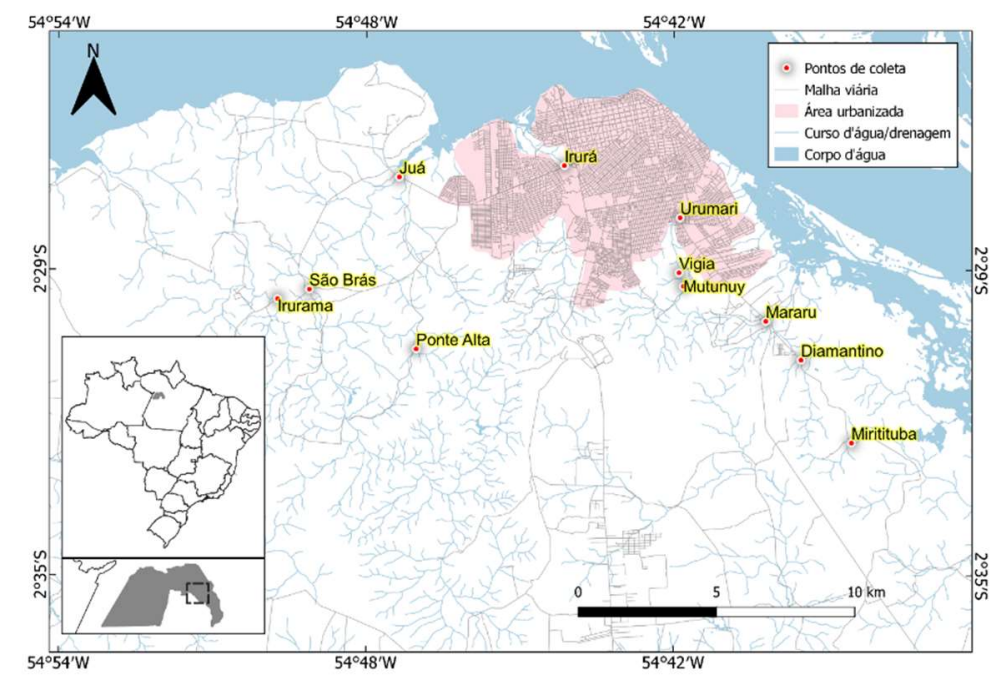

Figura 1: Mapa de localização da área de estudo e dos pontos amostrais. 
Após as coletas, as amostras de água foram devidamente armazenadas em um recipiente térmico e conduzidas ao Laboratório de Química Aplicada a Toxicologia, Saneamento Ambiental e Recursos Hídricos, da Universidade Federal do Oeste do Pará. No laboratório foram analisadas as concentrações de nitrito ( $\left.\mathrm{NO}_{2}\right)$, nitrato $\left(\mathrm{NO}_{3}{ }^{-}\right)$, amônia $\left(\mathrm{NH}_{3}\right)$, amônio $\left(\mathrm{NH}_{4}{ }^{+}\right)$, fosfato $\left(\mathrm{PO}_{4}{ }^{3-}\right)$, sulfato, potássio (K) e demanda química de oxigênio (DQO). Os métodos usados para a determinação dos parâmetros de matéria orgânica e de nutrientes estão descritos na Tabela 1. Falta discriminar o método usado para as análises microbiológicas, além da análise microbiológica. Parâmetros físico-químicos como oxigênio dissolvido (OD), temperatura da Água, turbidez, condutividade elétrica, $\mathrm{pH}$, sólidos totais dissolvidos (STD) foram determinados in loco.

Tabela 1: Equipamentos e métodos analíticos utilizados para análise dos parâmetros físico-químicos

\begin{tabular}{|c|c|c|c|}
\hline Variável & Modelo & $\begin{array}{ll}\text { Faixa } & \text { de } \\
\text { Deteç̧ão } & \\
\end{array}$ & Método \\
\hline OD & Oxímetro (55 YSI) & 0 a $20 \mathrm{mg} / \mathrm{L}$ & \multirow{4}{*}{$\begin{array}{l}\text { Galvânico, Clark (níquel/chumbo) } \\
\text { Galvânico, Clark (níquel/chumbo) } \\
\text { Arnold O. Beckman, } 1940 \\
\text { (espectrofotometrico) Nefelométrico } \\
\text { Karl Fischer, } 1935\end{array}$} \\
\hline Temperatura & Oxímetro (55 YIS) & -5 a $45 \circ C$ & \\
\hline Turbidez & Turbidímetro (AP 200 PoliControl) & 0,0 a 1000 NTU & \\
\hline $\begin{array}{l}\text { Condutividade } \\
\text { Elétrica }\end{array}$ & Condutivímetro (EC 300 EcoSense) & 0 a $499,9 \mu \mathrm{S} / \mathrm{cm}$ & \\
\hline pH & Phmetro (60 YSI) & 0 a 14 & \multirow{2}{*}{$\begin{array}{l}\text { (Eletrométrico) } \\
\text { Karl Fischer, } 1935 \\
\text { (Eletrométrico) } \\
\text { Karl Fischer, 1935 } \\
\text { (Eletrométrico) }\end{array}$} \\
\hline STD & Condutivímetro (EC 300 EcoSense) & 0,30 a 1,00 & \\
\hline DQO & $\begin{array}{l}\text { Fotômetro Multiparamétrico (HI } 83099 \\
\text { Hanna) }\end{array}$ & 0 a $150 \mathrm{mg} / \mathrm{L}$ & \multirow{4}{*}{$\begin{array}{l}\text { Arnold O. Beckman, } 1940 \\
\text { Dicromato, Sulfato de Mercúrio } \\
\text { (espectrofotometrico) } \\
\text { Arnold O. Beckman, } 1940 \\
\text { (espectrofotometrico)Nessler } \\
\text { Arnold O. Beckman, 1940 } \\
\text { (espectrofotometrico) Diazotação. } \\
\text { Arnold O. Beckman,1940 } \\
\text { (espectrofotometrico)Redução } \\
\text { cádmio. }\end{array}$} \\
\hline Amônia & $\begin{array}{l}\text { Fotômetro Multiparamétrico (HI } 83099 \\
\text { Hanna) }\end{array}$ & 0.0 a $3.00 \mathrm{mg} / \mathrm{L}$ & \\
\hline Nitrito & $\begin{array}{l}\text { Fotômetro Multiparamétrico (HI } 83099 \\
\text { Hanna) }\end{array}$ & 0.0 a $1.15 \mathrm{mg} / \mathrm{L}$ & \\
\hline Nitrato & $\begin{array}{l}\text { Fotômetro Multiparamétrico (HI } 83099 \\
\text { Hanna) }\end{array}$ & 0.0 a $30.0 \mathrm{mg} / \mathrm{L}$ & \\
\hline Fosfato & $\begin{array}{l}\text { Fotômetro Multiparamétrico (HI } 83099 \\
\text { Hanna) }\end{array}$ & 0.0 a $2.50 \mathrm{mg} / \mathrm{L}$ & Ácido Ascórbico \\
\hline
\end{tabular}

\section{Análise dos dados}

Os resultados das análises de águas superficiais foram comparados com a legislação vigente do Conselho Nacional de meio Ambiente (CONAMA), utilizando a resolução № 357 que estipula a classificação dos corpos de água e diretrizes ambientais para o seu enquadramento, bem como estabelece as condições e padrões de lançamento de efluentes, além de providências para as águas superficiais.

\section{RESULTADO E DISCUSSÃO}

\section{Análises de água superficial}

Os resultados das análises físicas-químicas das águas superficiais, foi analisado em consonância com que preconiza a Resolução 357/2005 (CONAMA, 2005) do Conselho Nacional de Meio Ambiente - CONAMA. Observamos variação significativas, nas concentrações de fosforo e coliformes, fora dos padrões de qualidade de água conforme apresentado na Tabela 2. 
Tabela 2: Valor máximo permitido pela legislação de água superficial.

\begin{tabular}{llll}
\hline Parâmetros & Classe 1 VMP & Classe 2 VMP & Classe 3 VMP \\
\hline Nitrito $\left(\mathrm{NO}_{2}{ }^{-}\right)$ & $1,0 \mathrm{mg} / \mathrm{L}$ & $1,0 \mathrm{mg} / \mathrm{L}$ & $1,0 \mathrm{mg} / \mathrm{L}$ \\
Nitrato $\left(\mathrm{NO}_{3}{ }^{-}\right)$ & $10,0 \mathrm{mg} / \mathrm{L}$ & $10,0 \mathrm{mg} / \mathrm{L}$ & $10,0 \mathrm{mg} / \mathrm{L}$ \\
Amônia $\left(\mathrm{NH}_{3}{ }^{+}\right)$ & -- & -- & -- \\
Fosforo $(\mathbf{P})$ & $0,020 \mathrm{mg} / \mathrm{L}$ & $0,020 \mathrm{mg} / \mathrm{L}$ & $0,15 \mathrm{mg} / \mathrm{L}$ \\
DQO & -- & -- & -- \\
Coliformes termotolerantes & 200 & 1.000 & 2500 \\
\hline
\end{tabular}

Na Tabela 3 estão apresentados os resultados das analise físico química e microbiologias referente os onze córregos da Região Oeste do Pará.

Entre os gradientes de demanda química de oxigênio (DQO), parâmetro clássico de poluição dos ambientes aquáticos, obtidos nos córregos observados a matéria orgânica apresenta-se diluída considerando que estes são águas urbanas ou corpos receptores. Os cursos d'água em questão encontram-se em avançado estágio de degradação ambiental devido a emissões contínuas e frequentes de efluentes domésticos, retirada da mata ripária, ligações clandestinas de esgoto, ausência de gestão de resíduos sólidos decorrente da ocupação imobiliária sem planejamento. Tal cenário, agrava a capacidade de autodepuração destes ambientes urbanos degradando-os rapidamente. A distribuição, nos corpos receptores, destes gradientes de matéria orgânica pode sofrer flutuações significativas, em períodos de precipitação intensa, pela diluição e da eventual sazonalidade de emissões (ALVES et al., 2010; D’ALESSANDRO et al., 2015; ALMEIDA et al., 2017). A presença de DQO (material orgânica biodegradável ou não) relativiza o decaimento das concentrações de oxigênio dissolvido no meio. Os gradientes de DQO presentes nos córregos urbanos de Santarém mostram um pico no córrego do Juá e um vale no córrego do Irurá. O córrego do Juá drena o total de efluentes domésticos gerados por um bairro novo da cidade de Santarém. Por outro lado, o córrego do Irurá, embora urbano ainda possui capacidade de autodepuração da carga orgânica.

Podemos observar que a concentração de nitrito não apresenta variações significativas em nenhum córrego. Destacamos que a concentração de nitrato embora dentro dos limites de tolerância preconizado pela legislação vigente apresentou valores mais elevados nos córregos do Miritituba, Irurama e Mararú sendo: 5,8; 4,1 e 3,7 mg/L respectivamente. O nitrito é um composto de presença intermediária, produto gerado por duas vias de estabilização do nitrogênio, nitrificação da amônia e da desnitrificação. De modo geral, as concentrações de nitrito são baixas exceto quando se apresentam condições ambientais alteradas (hipóxia), decorrente do maior aporte de carga orgânica poluidora, condição que incrementa a respiração microbiana em meio redutor (SILVA et al., 2014). Bastos (2007) sugere que a presença do nitrito em águas superficiais indica a ocorrência de processos biológicos ativos influenciados por poluição orgânica. Os córregos Marararu, Juá e Diamantino mostram ocorrência de nitrito ao contrário dos demais oito córregos observados, tal situação talvez possa ser explicada pela maior ocupação e uso do solo sem serviços de saneamento e urbanização encontrados nessas localidades.

Considerando que os córregos observados estão situados entre as classes 2 e 3 para qualidade de efluentes, em função de suas naturezas, as concentrações para nitrito encontram-se inteiramente dentro dos parâmetros estabelecidos pela legislação em vigor no Brasil (Tabelas 2 e 3). As formas inorgânicas do nitrogênio presentes na coluna d'água para Esteves (2011) estão intimamente relacionadas a produção e 
decomposição da matéria orgânica.

Ao contrário do íon nitrito a distribuição do nitrato nas águas superficiais apresenta maior concentração próximo a zona aerada superficial do córrego. A carga de efluentes libera nitrogênio no córrego por meio da degradação da matéria orgânica através da amonificação, sendo o nitrogênio amoniacal rapidamente transformado em nitrito e nitrato pelo processo de nitrificação (em anaerobiose), ao que leva a elevados gradientes de nitrato. Em condições ambientais benignas e em estado de equilíbrio o ambiente aquático rapidamente tampona o nitrato por meio do fitoplâncton. Entretanto, em condições ambientais alteradas por emissões contínuas e frequentes de carga orgânica, a presença de elevadas concentrações de nitrato pode conduzir ao processo de eutrofização (ANDRADE $t$ al., 2007; PINHEIRO et al., 2013; SILVA et al., 2014). Nesse estudo, apenas os córregos Vigia, Ponte alta, Juá e Diamantino não mostram presença de nitrato, todos os demais córregos apresentam gradientes acima dos valores indicados pela Resolução CONAMA 357/05 (CONAMA, 2005) para as classes 2 e 3.

Os gradientes de nitrogênio amoniacal encontrados nos córregos observados estão de acordo com que preconiza a Resolução CONAMA 357/05 e de acordo com as classes 2 e 3 (CONAMA, 2005). Biogeoquimicamente a amônia é o produto final da estabilização do nitrogênio orgânico (nitrogênio orgânico dissolvido e nitrogênio orgânico particulado) mediado por micro-organismos, processo este conhecido por amonificação (YOON et al., 2015; MCMILLAN et al., 2017). O sedimento é o principal sítio de amonificação nos corpos hídricos. Entre os córregos observados os gradientes de nitrogênio amoniacal estão adequados a Resolução CONAMA 357/05 considerando a alcalinidade do meio que naturalmente é baixa em águas da região amazônica. Gradientes baixos de amônia presentes na coluna d 'água podem revelar a aceleração das reações de nitrificação (CORREIA et al., 2015), o que pode ser confirmado pelos gradientes de nitrato observados. Por outro lado, gradientes de nitrogênio amoniacal são naturalmente inferiores na coluna d'água quando comparado com os encontrados no sedimento límnico.

A legislação não estabelece limite mínimo e máximo para a amônia, no entanto, podemos inferir que nos córregos da Ponte Alta, Mararú e Miritituba foram encontradas as maiores concentrações desses nutrientes sendo: 0,$25 ; 0,21$ e $0,19 \mathrm{mg} / \mathrm{L}$ respectivamente.

Passivos ambientais como a eutrofização são provocados pela presença de gradientes de fósforo na água. A amplitude dos gradientes de fósforo observados nos córregos foi maior no córrego Diamantino e ausente nos córregos Vigia, Mutunuy, Irurá e Urumari, apresentaram valores superiores aos limites estabelecidos para as classes 1 e 2, destacamos que, os córregos do Juá, São Braz e Irurama apresentaram concentrações de $0,10 \mathrm{mg} / \mathrm{L}$ no limite máximo de tolerância que é $0,15 \mathrm{mg} / \mathrm{L}$. Os córregos do Diamantino, Mararú e Ponte Alta apresentaram concentrações 4; 2,7 e 2 vezes superior ao limite máximo preconizado para a classe 3 respectivamente.

Os picos de fósforo ocorreram nos córregos Mararú, Ponte Alta e Diamantino provavelmente indicando que nestes pontos amostrais um maior potencial de hipernutrificação das águas considerando que o fósforo é o elemento limitante para desencadear a eutrofização cultural. Para que a desmobilização do fósforo a partir da matéria orgânica ocorra se dá por hidrólise enzimática (fosfatase), esse processo de 
estabilização é fundamental para a biodiposnibilidade de fosfato à biota (produtores primários e bactérias). A principal fonte de fósforo em águas urbanas decorre do esgotamento doméstico (BEFORE et al., 2008). Ambuhl (citado por ESTEVES, 2011) estimou que cada habitante seria responsável por eliminar 1,5 g de fósforo por dia por meio de dejetos e 2,7 g através de resíduos de produtos de limpeza.

Microorganismos patogênicos mostraram um pico no córrego do lururama e ausência completa no córrego Ponte Alta. Os gradientes observados nos córregos transitam entre as classes 2 e 3 da Resolução CONAMA 357/05. Conforme preconiza Sperling (1996) para coliformes termotolerantes a concentração crítica, do ponto de vista da legislação, situa-se no ponto de mistura efluente-rio, a partir desse ponto a concentração tende ao decaimento.

A menor concentração de DQO foi $35,5 \mathrm{mg} / \mathrm{L}$ no córrego do Irurá e nos outros córregos as concentrações variaram entre 70 e $97 \mathrm{mg} / \mathrm{L}$. Importante inferir também que a legislação vigente não estabelece limites mínimo e máximo de DQO, mais os resultados nos permite observar que as concentrações encontradas estão baixas e dentro do esperado para os córregos das regiões.

Somente no córrego da Ponte Alta, podemos observar que a concentração de coliformes termotolerantes está dentro dos limites estabelecidos para a classe 1 . Os outros córregos estão todos em consonância com a classe 2, destacando somente o córrego do Irurama que apresentou uma concentração de 2100 NMP/L muito próximo do limite mínimo preconizado para a classe 3 que é de 2500 NMP/L.

Tabela 3: Resultado dos parâmetros físico-químicos e microbiológicos das águas superficiais dos onze principais córregos da região Oeste do Pará.

\begin{tabular}{|c|c|c|c|c|c|c|c|c|c|c|c|}
\hline Parâmetros & $\begin{array}{l}\text { Urumar } \\
\text { í }\end{array}$ & Juá & $\begin{array}{l}\text { Vigi } \\
a\end{array}$ & $\begin{array}{l}\text { Mirititub } \\
\text { a }\end{array}$ & $\begin{array}{l}\text { Diamantin } \\
\text { o }\end{array}$ & $\begin{array}{l}\text { Marar } \\
\text { ú }\end{array}$ & Irurá & $\begin{array}{l}\text { Mutunu } \\
\text { y }\end{array}$ & $\begin{array}{l}\text { São } \\
\text { Bra } \\
z\end{array}$ & $\begin{array}{l}\text { Pont } \\
\text { e Alta }\end{array}$ & $\begin{array}{l}\text { Iruram } \\
\text { a }\end{array}$ \\
\hline $\begin{array}{l}\text { Nitrito }\left(\mathrm{NO}_{2}^{-}\right) \\
(\mathrm{mg} / \mathrm{L})\end{array}$ & 0,00 & $\begin{array}{l}0,0 \\
1\end{array}$ & 0,00 & 0,00 & 0,08 & 0,01 & 0,00 & 0,00 & 0,00 & 0,00 & 0,00 \\
\hline $\begin{array}{l}\text { Nitrato }\left(\mathrm{NO}_{3}^{-}\right) \\
(\mathrm{mg} / \mathrm{L})\end{array}$ & 2,40 & $\begin{array}{l}0,0 \\
6\end{array}$ & 0,00 & 5,80 & 0,00 & 3,70 & 1,65 & 0,00 & 2,80 & 0,00 & 4,10 \\
\hline $\begin{array}{l}\text { Amônia }\left(\mathrm{NH}_{3}^{+}\right) \\
(\mathrm{mg} / \mathrm{L})\end{array}$ & 0,15 & $\begin{array}{l}0,1 \\
4\end{array}$ & 0,14 & 0,19 & 0,10 & 0,21 & 0,18 & 0,00 & 0,14 & 0,25 & 0,11 \\
\hline $\begin{array}{l}\text { Fosforo (P) } \\
\text { (mg/L) }\end{array}$ & 0,00 & $\begin{array}{l}0,1 \\
0\end{array}$ & 0,0 & 0,2 & 0,60 & 0,40 & 0,00 & 0,00 & 0,10 & 0,30 & 0,10 \\
\hline $\begin{array}{l}\mathrm{DQO} \\
(\mathrm{mg} / \mathrm{L})\end{array}$ & 95 & 97 & 90 & 77 & 88 & 70 & $\begin{array}{l}35,5 \\
0\end{array}$ & 85 & 86 & 75 & 87 \\
\hline $\begin{array}{l}\text { Coliformes } \\
\text { termotolerant } \\
\text { e } \\
\text { (NMP/100 mL) }\end{array}$ & 680 & 810 & 1000 & 550 & 920 & 610 & 950 & 1400 & 680 & 0,00 & 2100 \\
\hline
\end{tabular}

\section{CONCLUSÕES}

Considerando a qualidade da água para os córregos observados e sua natureza urbana é importante um programa de monitoramento e controle destas coleções de água assim como a restauração das zonas ripárias para que diminuam inundações e cargas de sedimento para dentro dos canais permitindo assim que atividades antrópicas compatíveis com as classes 2 e 3 da Resolução CONAMA 357/05 possam ser oferecidas com segurança. 


\section{REFERÊNCIAS}

ALMEIDA, E. C. O.; KAZAK, C.; FERNANDES, C. V. S.. Influência da sazonalidade no índice de qualidade das águas, no Rio Iguaçu. In: SIMPÓSIO BRASILEIRO DE RECURSOS HÍDRICOS 22. Anais. 2017.

ALVES, M. L.; OLIVEIRA, L. R.; FRADE, P. R.; CUNHA, H. P.. Qualidade de água urbana e rural no Munícipio de Formiga/MG. In: CONGRESSO DE PÓS-GRADUAÇÃO DA UFLA, 19. Anais. 2010.

ANA. Agência Nacional de Águas. Indicadores de qualidade: Índice de qualidade das águas (IQA). Brasília: ANA, 2011.

ANDRADE, E. M.; ARAUJO, F. P.; ROSA, M. F.; GOMES, R. B.; LOBATO, F. A. O.. Fatores determinantes da qualidade das águas superficiais na Bacia do Alto Acaraú, Ceará, Brasil. Ciência Rural, v.37, n.6, p.1791-1797. 2007.

BASTOS, R. K.; BEZERRA, N. R.; BEVILACQUA, P. D.. Planos de Segurança da Água: Novos Paradigmas em Controle de Qualidade da Água para Consumo Humano em Nítida Consonância com a Legislação Brasileira. In: CONGRESSO BRASILEIRO DE ENGENHARIA SANITÁRIA E AMBIENTAL. Anais. Belo Horizonte, 2007. p.391.

BEFORE, P. D.; DAVID, M. B.; STUCKI, J. W.. Mechanisms of Phosphorus Control in Urban Streams Receiving Sewage Effluent. Water Air Solo Pollut, v.191, p.217-229, 2008. DOI: http://doi.org/10.1007/s11270-008-9619-x

CONAMA. Conselho Nacional de meio Ambiente. Resolução n.357, de 17 de março de 2005. Brasília: CONAMA, 2005.

CORREIA, L. J. H.; FERNANDES, A. J. D.; LÚCIO, M. M. L. M.; TOMAZ, J. K. O.; HONORATO, M. B.; CARNEIRO, E. N.. Monitoramento da qualidade físico-química da água do estuáriodo Rio Paraíba, Cabedelo, PB. Revista Principia, n.27, p.47-54. 2015.

D'ALESSANDRO, E. B.; SAAVEDRA, N. K.; SANTIAGO, M. F.; DÁLESSANDRO, N. C. O.. Influência da sazonalidade em lagoas de estabilização. Ingeneria Del Água, v.19, n.4, p.193209. 2018.

ESTEVES, F. A.. Fundamentos de limnologia. Rio de Janeiro: Interciência. 3 ed. 2011.

JUSTINO, E. A.; PAULA, H. M.; PAIVA, E. C. R.. Análise do efeito da impermeabilização dos solos urbanos na drenagem de água pluvial do município de Uberlândia-MG. Espaço em Revista, v.13, n.2, 2011.

MANOEL, L. M.; SANT'ANNA, I. B.; CARVALHO, S. L. Avaliação da Demanda Bioquímica de Oxigênio (DBO) como parâmetro de poluição na Bacia Hidrográfica do Córrego
Caçula/SP. Periódico Eletrônico Fórum Ambiental da Alta Paulista, v.15, n.4, 2019.

MCMILLAN, S. K.; NOE, G. B.. Increasing floodplain connectivity through urban stream restoration increases nutrient and sediment retention. Ecological Engeneering, v.108, p.284-295. 2017. DOI:

https://doi.org/10.1016/i.ecoleng.2017.08.006

OLIVEIRA, F. R.; CECILIO, R.; ZANETTI, S. S.; FERRAZ, F. T.. Caracterização hidroambiental como indicador de qualidade de água em nascentes. Caminhos de Geografia, v.21, n.74, p.276-294, 2020.

PINHEIRO, A.; KAUFMANN, V.; SCHNEIDERS, P.; OLIVEIRA, D. A.; ALBANO, R. M. R.. Concentrações e cargas de nitrato e fosfato na Bacia do rio Ribeirão Concórdia, Lontras, SC. Revista Brasileira de Engenharia Agrícola e Ambiental, v.17, n.1, p.86-93, 2013.

PINTO, A. G. N.; HORBE, A. M. C.; SILVA, M. S. R.; MIRANDA, S. A. F.; PASCOALOTO, D.; SANTOS, H. M. C.. Efeitos da ação antrópica sobre a hidrogeoquímica do rio Negro na orla de Manaus/AM. Acta Amazônica, v.39, n.3, p.627-638, 2009.

SANTOS, R. F.; SANTOS, Z.; SOUSA, M. S.; LOPES, R. B.; MOURA, S. M.. Modelagem matemática da autodepuração da microbacia do Irurá no Município de Santarém, Pará. Revista Tecnologia, v.41, n.1, 2020.

SILVA, G. F.; SANTOS, M. M.; CELLIGOI, A.; FAZOLO, A.. Avaliação das concentrações de nitrato e nitrito à jusante do antigo lixão do Munícipio de Rolândia -PR. In: CONGRESSO BRASILEIRO DE ÁGUAS SUBTERRÂNEAS, 18. Anais. 2014.

SOUZA, M.. Transamazônica: integrar para não entregar. Nova Revista Amazônica, v.8, n.1, p.133-152, 2020.

SPERLING, M. V.. Introdução à qualidade das águas e ao tratamento de esgotos. 2 ed. Belo Horizonte: Escola de Engenharia da UFMG, 1996.

TOLEDO, L. G.; NICOLELLA, G.. Índice de qualidade de água em microbacia sob uso agrícola e urbano. Scientia Agricola, v.59, n.1, p.181-186, 2002.

TRATA BRASIL. Instituto Trata Brasil. Estudo Benefícios Econômicos e sociais da expansão do Saneamento no Brasil. TRATA BRASIL, 2017.

YOON, S.; GARCIA-CRUZ, C.; SANFORD, R.; RITALAHTI, K. M.; LOFFLER, F. E.. Denitrification versus ammonification respiratory: environmental controls of two comporting dissimilatory $\mathrm{NO}_{3} / \mathrm{NO}_{2}$ reduction pathways in Skewanella loihica strain PV-4. The Isme Journal, v.9, p.1093-1104, 2015.

A CBPC - Companhia Brasileira de Produção Científica (CNPJ: 11.221.422/0001-03) detém os direitos materiais desta publicação. Os direitos referem-se à publicação do trabalho em qualquer parte do mundo, incluindo os direitos às renovações, expansões e disseminações da contribuição, bem como outros direitos subsidiários. Todos os trabalhos publicados eletronicamente poderão posteriormente ser publicados em coletâneas impressas sob coordenação da Sustenere Publishing, da Companhia Brasileira de Produção Científica e seus parceiros autorizados. Os (as) autores (as) preservam os direitos autorais, mas não têm permissão para a publicação da contribuição em outro meio, impresso ou digital, em português ou em tradução. 